\title{
Mudanças Históricas nos Ruídos da Cidade: A Paisagem Sonora Urbana como uma Composição Musical
}

\author{
Historical Changes in the City Noises: Soundscape as a Musical Composition \\ Cambios históricos em los ruídos de la ciudad: El paisaje sonoro urbano como \\ composición musical
}

\author{
Helena Rodi Neumann \\ Professora Doutora, UFMS, Brasil \\ helena.neumann@ufms.br \\ Odirlei Neumann \\ Mestrando, UFMS, Brasil.

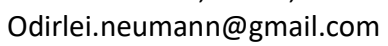




\section{RESUMO}

Neste artigo pretende-se sintetizar as mudanças dos sons da cidade ao longo do processo de desenvolvimento histórico da sociedade. A revisão literária se baseia principalmente no trabalho do autor canadense Murray Schafer, que definiu o conceito de paisagem sonora ou "Soundscape" em 1979, sendo o mais consagrado autor sobre o tema. Para descrever a evolução do ambiente sonoro urbano, primeiramente se apresenta a diferenças entre a paisagem sonora natural e a consolidada após o rápido processo de urbanização. A discussão é feita considerando os principais eventos históricos que alteraram os ruídos urbanos: A chegada dos sons tecnológicos com a Revolução Industrial; o aumento exponencial do ruído dos meios de transporte e o impacto da Revolução Elétrica. Como conclusão se realiza uma análise a respeito da cultura contemporânea em comparação com a paisagem sonora das cidades. O caos sonoro como retrato da sociedade atual.

PALAVRAS-CHAVE: Ruído Urbano; Paisagem Sonora; Murray Schafer; Cidade Contemporânea.

\section{ABSTRACT}

This article intends to synthesize the city sounds changes throughout the process of historical society development. The literary review is based mainly on the work of the Canadian author Murray Schafer, who defined the concept of Soundscape in 1979, being the most authored author on the subject. In order to describe the evolution of the urban sound environment, it first presents the differences between the natural and consolidated soundscape after the fast urbanization process. The discussion is made considering the main historical events that changed the urban noises: The arrival of technological sounds with the Industrial Revolution; the exponential increase of the transport noise and the impact of the Electric Revolution. As a conclusion an analysis is made regarding contemporary culture in comparison with the soundscape of the cities. Sound chaos as a portrait of the present society.

KEY WORDS: Urban Noise; Sound Landscape; Murray Schafer; Contemporary City.

\section{RESUMEN}

En este artículo se pretende sintetizar los cambios de los sonidos de la ciudad a lo largo del proceso de desarrollo histórico de la sociedad. La revisión literaria se basa principalmente en el trabajo del autor canadiense Murray Schafer, que definió el concepto de paisaje sonoro o "Soundscape" en 1979, siendo el más consagrado autor sobre el tema. Para describir la evolución del ambiente sonoro urbano, primero se presentan las diferencias entre el paisaje sonoro natural y la consolidada después del rápido proceso de urbanización. La discusión se hace considerando los principales acontecimientos históricos que alteraron los ruidos urbanos: La llegada de los sonidos tecnológicos con la Revolución Industrial; el aumento exponencial del ruido de los medios de transporte y el impacto de la Revolución Eléctrica. Como conclusión se realiza un análisis acerca de la cultura contemporánea en comparación con el paisaje sonoro de las ciudades. El caos sonoro como retrato de la sociedad actual.

PALABRAS CLAVE: Ruido Urbano; Paisaje Sonora; Murray Schafer; Ciudad Contemporánea. 


\section{INTRODUÇÃO}

Os novos sons da cidade se diferenciam em qualidade e intensidade dos antigos. Os sons tradicionais, como eventos de música, podem ser os mesmos. Os sons naturais, como o produzido pelos ventos e pássaros, também podem ser similares. Porém, a grande diferença é a proximidade das fontes sonoras, que encontramos em uma cidade em estado de saturação. $\mathrm{Na}$ verdade, até mesmo o vento, devido a proximidade dos edifícios, não gera seu som original, devido a mudança na configuração espacial. Os pássaros acontecem em menor número que antes, devido a carência de áreas verdes nas cidades contemporâneas.

Tudo mudou, a paisagem sonora se transforma junto com as mudanças no modo de vida da sociedade, mas isso não significa que muda sempre para pior. Porém, é fundamental compreender essa mudança, afinal o Homem sofre a interferência do meio em que vive. E não apenas com o impacto psicológico, mas também o fisiológico, na medida em que nosso corpo fica em um estado de tensão inevitável quando submetido a ruídos intensos.

A poluição sonora é atualmente um problema mundial, que deve ser controlado rapidamente, para evitar danos a saúde coletiva. Como afirma o ecologista Eugene Odum: "Ambas as formas de poluição do ar (sonora e química) são comuns em cidades em situação de saturação" (ODUM apud SCHMID, 2005, p.259). O principal fator que gera a poluição sonora no espaço urbano são os meios de transporte, principalmente o rodoviário. O número de carros, ônibus, motocicletas, trens, aviões, etc., é muito maior que antes. Atualmente, pesquisas tecnológicas tentam reduzir ruídos produzidos por estes motores, mas diversos aspectos estão correlacionados, como o tipo de pavimento das pistas de rodagem, até as condições climáticas do local, como será discutido neste artigo. Deve-se compreender que é o ritmo da cidade que configura sua paisagem sonora, e no passado, este movimento era bem mais calmo, com menos informações sonoras de fontes distintas.

Ao se avaliar uma paisagem sonora, pode-se compreender culturalmente uma sociedade. Porém, é muito difícil retratar uma expressão sonora exata de mesma, ou seja, é muito difícil descrever todos os sons presentes no cotidiano da uma cidade. Na língua inglesa, o conceito de paisagem sonora é chamado de soundscape (SCHAFER, 1977), que se relaciona à palavra landscape, que significa a paisagem na sua compreensão visual. A paisagem visual é muito mais fácil de se reter, uma vez que não existe nada na acústica que corresponda a impressão instantânea que uma fotografia é capaz de produzir. Porém o som impressiona mais, afinal a visão se relaciona com nossa razão, enquanto a audição nos sensibiliza emocionalmente.

\section{REVISÃO DE LITERATURA}

O livro escolhido para a elaboração do referencial teórico sobre Paisagem Sonora foi o do autor Raymond Murray Schafer, que definiu este conceito no final da década de 1970. Este é um consagrado compositor canadense nascido em 1933, que ficou conhecido com sua pesquisa sobre ambientes acústicos no trabalho World Soundscape Project, desenvolvido na Universidade Simon Fraser, em Burbany, Canadá. O autor também é um pianista consagrado, 
que posteriormente dedicou grande parte de suas pesquisas sobre métodos de ensinar música para crianças.

Apresentam-se neste artigo as teorias presentes em sua principal obra, que foi publicada em 1977 com o título de The Tunning of the World, e republicada me 1994 com o nome de The Soundscape. Este livro reúne e também busca organizar textos e outras publicações do autor, em particular dos livros The New Soundscape e do The Book of Noise, além de diversos documentos do próprio World Soundscape Project (SCHAFER, 1977). É certamente o livro mais representativo de sua obra como ambientalista da ecologia acústica, designação esta devido a seus trabalhos com ênfase em preservar a natureza física dos ambientes e a paisagem sonora composta por todos os sons que permeiam o espaço. Como define Gordon Hempton, "Para mim, um ecologista acústico é, acima de tudo, uma pessoa que sabe escutar. O que fazemos é tratar todos os sons com igual importância para saber interpretá-los" (HEMPTON, 2011). A proposta é reconhecer que a paisagem sonora é um retrato da sociedade, e por isso, é preciso interpretá-la para entender uma sociedade, em certo momento histórico.

Schafer introduz o livro dizendo que "a paisagem sonora do mundo está mudando" 1 (SCHAFER, 1977, p.3). O Homem moderno (final da década de 1970) começa a habitar um mundo com um ambiente acústico radicalmente diferente de tempos antigos. Nos séculos passados, a aglomerações urbanas não se encontravam em estado de saturação, tanto de habitantes, quanto de meios de transporte. A concentração normalmente causa problemas sonoros, devido à proximidade das fontes sonoras. Quanto mais densa uma cidade, e mais heterogênea em relação aos usos, mais ruidosa esta será. Outra questão que se diferencia do passado é a dinâmica da vida contemporânea, como será discutido a seguir.

É necessário sempre correr contra o tempo, e com este intuito, estamos sempre em movimento, em trânsito. E quanto mais atividade, mas sons são produzidos. Em uma metrópole contemporânea, o seu atual ritmo frenético é facilmente verificável através da compreensão da paisagem sonora: os ruídos do tráfico rodoviário, que se intensificam nos horários de pico; o aviões passando; as ruas com rotas de ônibus; as constantes obras da construção civil; o fluxo de pedestres nas ruas; a música dos bares; o latido dos diversos cachorros; além das atividades eventuais.

A pergunta central dos pesquisadores sobre a Paisagem Sonora é "qual é a relação entre o Homem e os sons do ambiente e o que acontece quando esses sons mudam?" (SCHAFER, 1977, p.4). A poluição sonora só acontece quando o Homem ignora os sons do ambiente; e, por isso, não busca amenizá-los, como em casos como a falta de planejamento urbano nas cidades que permitem a construção de edifícios de usos sensíveis (como habitações, escolas, hospitais) próximas a rodovias de grande porte, que são frequentes nas metrópoles brasileiras, que são extremamente ruidosas. Deve-se buscar amenizar as fontes de ruído, porém algumas sempre vão produzir ruídos, e por isso que é necessário um distanciamento mínimo de outras edificações.

\footnotetext{
1 "The soundscape of the world is changing".
} 
O autor defende que o estudo da acústica urbana não deve apenas propor formas de excluir ruídos, porque nem todos estes são ruins. Como afirma Aloísio Schmid "dentro delas (edificações) podemos preferir o silêncio, mas quando estamos fora, sem a proteção do lar, privar-se da audição causa mais inquietude que serenidade, pois é um alheamento forjado do mundo real". (SCHIMID, 2005, p.260) Há uma preocupação maior com os sons no interior de edifícios, porém os sons da cidade são mais representativos de certa cultura.

Deve-se, portanto, verificar quais os sons que devem ser preservados e multiplicados no meio urbano. A partir disso, os sons negativos, que são os que causam a formação de perturbação ao Homem, podem ser reconhecidos, demonstrando assim a necessidade de eliminá-los. "Só uma apreciação global da acústica do ambiente pode nos dar as fontes para melhorar a orquestração da paisagem sonora mundial." (SCHAFER, 1977, p.4), afirma Schafer, que constantemente defende a interpretação do ambiente sonoro de forma integrada, configurando um cenário geral.

Schafer então apresenta uma pergunta final, mas que neste artigo cabe como um questionamento de partida: "A paisagem sonora mundial é uma composição indeterminada sobre a qual não temos controle, ou nós somos seus compositores e artistas, responsáveis por dar a este forma e beleza?" (SCHAFER, 1977, p.5). Deve-se constatar que a paisagem sonora é algo controlável, e está fortemente conectada com as decisões projetuais e de gestão pública adotadas para um meio urbano, e por isso pode ser melhorada, basta não se negligenciar o problema. E que a consolidação de uma paisagem sonora urbana negativa, causa sim impactos prejudiciais ao Homem, tanto físicos quanto psicológicos.

Ao longo de todo o seu livro, o autor busca "tratar o mundo como uma composição musical macrocósmica" (SCHAFER, 1977, p.5). Para muitos pesquisadores seria inaceitável associar a música aos ruídos urbanos, por receio de diminuir sua importância, porém Schafer acredita que a música nada mais é do que sons. Os sons e os ruídos são exatamente o mesmo fenômeno, mas como diferencia Léa Cristina Souza "uma vez interferindo no bom andamento das atividades, nos objetivos dos espaços, prejudicando a função do ambiente, o som pode ser considerado ruído, independente do seu espectro". (SOUZA, ALMEIDA, BRAGANÇA, 2009, p.47) Porém, antes de avaliar um som como negativo, ou seja, classifica-lo como ruído, deve-se evitar julgamentos precipitados afim de compreender na tonalidade a paisagem sonora.

\section{EVOLUÇÃO DO AMBIENTE SONORO}

Quando se estuda o som ambiente, são necessárias diferentes amostragens dos eventos sonoros para se definir um contexto, ou seja, são feitas diversas percepções de sons momentâneos, em diferentes horários, para se compreender como a paisagem sonora local. 0 evento sonoro é exatamente um som momentâneo. Como define Schafer, "a paisagem sonora consiste em eventos que são escutados e não objetos vistos" (SCHAFER, 1977, p.8), e por esta razão ha dificuldade de apresentar um cenário único representativo. Com estas colocações cabe avaliar quais formas utilizar como meio de colaborar para a caracterização de uma paisagem sonora. 
Também é difícil recorrer à perspectiva histórica para análise de paisagens sonoras. Há uma grande desvantagem se considerada a paisagem visual, na qual diversas fotos antigas podem ser analisadas com o intuito de compreender um cenário passado. Como as avaliações e registros de decibels são recentes, na paisagem sonora apenas pode-se fazer suposições de suas mudanças ao longo dos anos.

Schafer, porém, remete à história para demonstrar a importância do sentido da audição. Conta que "antes dos dias da escrita, nos dias dos profetas e épicos, o sentido da audição era mais vital que a visão. A palavra de Deus, a história de tribo e todas as outras informações importantes eram escutadas, e não vistas" (SCHAFER, 1977, p.11). A audição tem um papel importante para a percepção do espaço a nossa volta.

A sociedade Européia, no geral, sempre valorizou mais a visão, como evidencia o ditado popular 'Ver para Crer'; e de certa forma espalhou essa cultura por muitas partes do mundo. Porém, como afirma Schafer, "A própria emergência da poluição sonora como um tópico de preocupação pública atesta a fato que o Homem moderno está finalmente começando a se preocupar em limpar a lama de suas orelhas e recuperar o talento para uma clairaundience audição limpa" (SCHAFER, 1977, p.11). O conceito definido pelo autor como clairaudience significa ter excepcionais poderes de audição, ou seja, ter consciência dos sons que se permite ouvir.

\section{PAISAGEM SONORA ORIGINAL}

Estes são os grandes problemas que caracterizam a cidade contemporânea, no viés da acústica: a falta de perspectiva, causada pela grande obstrução das diversas edificações, que resulta em uma percepção espacial deficiente, e assim o território é compreendido como 'terra de ninguém', e por isso é abandonado; o segundo problema são os níveis de ruído muito altos, que mascaram os sons agradáveis a vida cotidiana, como o cantar dos passarinhos, que só aumentam a tensão corporal do Homem e apoiam o ritmo frenético da vida urbana.

Como descreve Schafer, inicialmente "a paisagem sonora original era geralmente calma, mas foi deliberadamente pontuada pela aberração dos ruídos da guerra. A celebração religiosa era outra ocasião para ocorrência altos ruídos." (SCHAFER, 1976, p.51) Em tempos passados, mesmo as vilas possuíam um ritmo mais tranquilo, e somente os eventos destoantes como guerras alteravam a paisagem sonora, e sempre estavam atrelados a infelicidade.

Em relação a religião, seus sons precisavam ser eloquentes, afinal representam uma conexão divina, sobre-humana. Como acredita o autor "a palavra de Deus chegou até o homem originalmente através do ouvido, e não do olho. Ao reunir seus instrumentos e fazendo ruídos impressionantes, o Homem esperava por sua vez, chegar ao ouvido de Deus." (SCHAFER, 1976, p.51). As histórias bíblicas eram ouvidas, e apenas através de fé acreditadas.

A igreja foi o primeiro espaço interno no qual se explorou as propriedades da acústica, para gerar um espaço divino, do ponto de vista da introspecção Humana. Schafer descreve que "o interior da igreja reverberou os eventos mais espetaculares acústica, para este lugar o Homem trouxe não só a sua voz, elevada em música, mas também a mais sonora máquina que ele 
tinha até então produzido - o órgão". (SCHAFER, 1976, p.52) O timbre do órgão no interior reverberante das igrejas tornava o evento extraordinários aos ouvintes, ou melhor, certamente divino.

Como o próprio autor afirma que "Cidades pobres são mais silenciosas do que cidades prósperas." (SCHAFER, 1976, p.52) As cidadelas dos tempos passados não seguiam a lógica do capital, com seu lema 'tempo é dinheiro', e o ritmo cotidiano era muito mais ameno, e a qualidade de vida muito melhor. Deve-se avaliar nesta frase o sentido de prosperidade.

Não é desejável ter um ritmo de vida tão acelerado, no qual só se visa acumulação de capital, em detrimento da qualidade de vida. E além disso, é bom ter espaços públicos com qualidade na cidade, uma forma de lazer público. Se o espaço é melhor percebido, sem ruído em excessos, mascarando os sons bons; e se visuais forem abertas, melhorando nossa perspectiva deste espaço, a população vai se apropriar deste, e cuidá-lo melhor. Seguindo este pensamento, a seguir descreve-se sobre a consolidação da cidade.

\section{CONSOLIDAÇÃO DO URBANO}

Schafer acredita que "em termos de paisagem sonora, uma divisão prática no desenvolvimento urbano é, como em tantas outras áreas, a Revolução Industrial." (SCHAFER, 1976, p.52) Antes de entrar na discussão sobre a cidade pós-revolução industrial, aborda-se os ruídos presentes na consolidação das primeiras cidades, desde a Idade Média. Como descreve Schafer (1976, p.53):

Olhando para o perfil de uma cidade medieval européia, pode-se notar que o castelo, a muralha da cidade e da torre da igreja dominam a cena. $\mathrm{Na}$ cidade moderna é o arranha-céu, o edifício do banco e a chaminé de indústria, que são as estruturas mais altas. Isto muito nos diz sobre as proeminentes instituições sociais destas diferentes sociedades.

Os símbolos marcantes de uma cidade podem dizer muito sobre sua sociedade. Mesmo considerando as contemporâneas, podem-se fazer diversas distinções culturais. Além disso, dentro de uma mesma metrópole, como é o caso de São Paulo, os bairros podem ser muito diferentes. É necessário realizar uma análise precisa dos usos do local, e os pontos de concentração comunitária devem ser verificados, com o intuito de compreender com este espaço funciona, para assim caracterizar a sua paisagem sonora.

Porém, a simbologia não está apenas nas edificações marcantes. Os sinais sonoros são muito importantes para descrever uma sociedade, uma vez que imprimem um ritmo na mesma, como exemplifica o autor:

O sinal sonoro mais saliente na comunidade cristã é o sino da igreja. Este é capaz de definir a comunidade, já que a paróquia é um espaço sonoro, circunscrito no raio de influência do sino. O sino da igreja é um som central, que atrai e unifica a comunidade em um sentido social, e assim aproxima o Homem e Deus. (SCHAFER, 1976, p.54) 
O som sempre foi muito explorado pela religião devido sua capacidade de sensibilizar o emocional Humano. Mas também é fundamental salientar a capacidade do som de alertar, como no caso das sirenes de ambulâncias, e como consequências atrair a atenção, resultando em um potencial para a união. Música de rua costuma atrair a atenção dos pedestres, resultando em uma aglomeração.

Outro sinal sonoro posterior, mas de fundamental importância foi a torre do relógio. A edificação já se configurava com um marco na cidade, e os ruídos ditavam o ritmo da vida, como descreve:

Foi durante o século XIV que o sino da igreja foi comparado com uma invenção técnica de grande importância para a civilização européia: o relógio mecânico. Juntos, eles tornaram-se os sinais mais incontornáveis da paisagem sonora, pois, como o sino da igreja, e com pontualidade cada vez mais valorizada, o relógio mede a passagem do tempo de forma audível. (SCHAFER, 1976, p.55)

Schafer acrescenta que os "relógios regulam os movimentos da cidade com imperiosidade militante." (SCHAFER, 1976, p.56) Atualmente, perdeu-se estas relações de centralidade na cidade. Isso também está associado a falta de perspectiva no espaço público, o que impede a população de se referenciar por algum edifício central marcante.

Neste contexto, observa-se que "antes da Revolução Industrial, o trabalho muitas vezes se atrelava a música, pois os ritmos eram sincronizados com o ciclo de respiração humana, ou com hábitos de mãos e pés." (SCHAFER, 1976, p.63) Havia uma maior dedicação Humana para a percepção sonora, que era usada em conjunto com atividades de trabalho, configurando um ritmo mais ameno, porém mais equilibrado.

\section{Discussão: Chegada dos Sons TeCNológicos}

O grande marco para o início da mudança da paisagem sonora mundial foi a Revolução Industrial, como já mencionado anteriormente. Vários novos ruídos foram inseridos no dia-adia da população, e como explica Schafer "a Revolução Industrial introduziu uma infinidade de novos sons com consequências infelizes para muitos dos sons naturais e humanos que estes tendem a obscurecer". (SCHAFER, 1976, p.71) Os ruídos produzidos pelas máquinas começam a se sobressair aos sons naturais, e a paisagem sonora se torna cada vez mais artificial.

A análise da transformação na paisagem sonora é fundamental para a compreensão da percepção auditiva e espacial urbana da sociedade atual. Com os sons predominantes se tornando cada vez mais desinteressantes, o Homem se distancia do meio natural, e do espaço comum e público, para se proteger em local privado, onde a princípio tinha o total controle. Atualmente, é difícil evitar a poluição sonora até em espaços particulares.

A grande invenção do século XIX, porém, segundo o autor, foi a criação de um método de invenção. Diversas foram as invenções tecnológicas do período. Novas tecnologias geraram novas fontes sonoras, mas como coloca Schafer "levou tempo para que os sons da tecnologia se espalharem por toda a Europa. (...) Os novos sons foram gradualmente aceitos como 
inevitáveis." (SCHAFER, 1976, p.73) Em vez de se identificar o problema do ruído das máquinas, e buscar tecnologias para torná-las mais silenciosas, a população preferiu aceitar os mesmos.

O autor continua dizendo que "no início do século XX, os sons da tecnologia tornaram-se mais aceitáveis para o ouvido urbano, 'combinando' com os ritmos naturais da antiguidade." (SCHAFER, 1976, p.74) A medida que os ruídos das máquinas foram se tornando parte da memória do Homem, como parte da história de evolução da humanidade, os ruídos pareciam ser menos agressivos. Eram compreendidos como sons do progresso, o que explica a psicoacústica².

De qualquer modo, os ruídos das novas tecnologias invadiram a vida do Homem de forma decisiva. Schafer explica que "em última análise, o pulsar da máquina começou a intoxicar o homem em todos os lugares com suas vibrações incessantes." (SCHAFER, 1976, p.74) Ou seja, considerando ou não o costume com a situação, o fato é que a percepção do espaço mudou, uma vez que a audição nesta influencia.

No final do século XIX, são relatadas as primeiras reclamações sobre os ruídos industriais, mas somente cem anos depois critérios para o ruído foram estabelecidos como parte de programas de salubridade nas indústrias. Segundo o autor, desde 1830, já se sabia que o ruído poderia levar a surdez. Como descreve Schafer (1976, p.76):

\begin{abstract}
A incapacidade de reconhecer o ruído durante as primeiras fases da Revolução Industrial como um fator que contribui para multiplicar a toxicidade dos novos ambientes de trabalho é um dos fatos mais estranhos da história da percepção auditiva. Devemos tentar determinar a razão. Isto pode ser parcialmente explicado como resultado da incapacidade de medir quantitativamente os sons.
\end{abstract}

Apesar do conhecimento musical já ser bem desenvolvido no final do século XIX, agora estava levantada uma questão diferente em relação a acústica: a necessidade de controle de ruídos. Não era possível nem identificar corretamente os sons indesejáveis, muito menos quantificar este som em excesso. Como afirma Schafer "O Decibel, como um meio definitivo de estabelecer níveis de pressão sonora, não entrou em uso extensivo até 1928." (SCHAFER, 1976, p.76) Portanto, apenas a partir da década de 1930, que a unidade mais corrente para o estudo do controle de ruído foi de fato adotada.

Outra razão para que não houvesse reclamações em relação a ruídos muito intensos, segundo o autor, é que o som pode estar relacionado ao poder do superior, e o costume dos funcionários com situação parecia inevitável:

A associação de ruído e poder nunca foi realmente desfeita na imaginação humana. Ele descende de Deus, para o padre, para o industrial e, mais

\footnotetext{
${ }^{2}$ A psicoacústica estuda a relação entre sensações auditivas e as características físicas do som. As sensações auditivas são determinadas pelas características físicas do som, principalmente, frequência e amplitude, mas também características temporais.
} 
recentemente para a transmissor de rádio e o aviador. É importante entender o seguinte: para emitir o 'Ruído Sagrado' não basta apenas fazer o maior barulho, mas sim, é uma questão de ter a autoridade para fazê-lo sem censura. (SCHAFER, 1976, p.76)

O Homem sempre acreditou que Deus tinha o poder para fazer barulho, afinal ele é o grande criador, e os primeiros ruídos intensos escutados foram sempre produzidos por fenômenos naturais. Quando novas invenções surgiram, grandiosas e muito ruidosas, eram diretamente associadas ao poder divino, como continua Schafer:

\begin{abstract}
Nós já notamos como altos ruídos evocavam medo e respeito no passado, e como eles pareciam ser a expressão do poder divino. Observamos, também, como esse poder foi transferido de sons naturais (trovão, vulcão, tempestade) para os sons do sino da igreja e do órgão. Durante a Revolução Industrial, o 'Ruído Sagrado' se espalhou por todo o mundo profano. (SCHAFER, 1976, p.76)
\end{abstract}

A partir da Revolução Industrial, os sons das máquinas começam a se espalhar e impactar a paisagem sonora cotidiana da população. Neste momento também surge um questionamento do papel da Igreja, e seu real caráter divino, uma vez que a Indústria consegui tirar deste seu monopólio de poder. E com o novo modo de vida mais acelerado, em razão do aumento nas jornadas de trabalho dos operários, restava menos tempo para a religião. Mas em seguida, os sons intensos começam a se popularizar, e gradativamente vão perdendo seu caráter simbólico atrelado ao poder, para se tornar uma característica inevitável da paisagem.

Em resumo, pode-se dizer que o som possui uma grande carga simbólica, e tem a característica fundamental de transmitir ideias de forma abrangente. Mas o Homem, até na contemporaneidade, não deu muita importância para seu estudo e controle. Os ruídos são compreendidos como consequência de outros fatores, e nada pode feito para melhorar a paisagem sonora. Somente agora que a poluição sonora se torna insuportável nas grandes metrópoles, o assunto começa a ser debatido com maior frequência.

\title{
6 RUÍDO DOS TRANSPORTES
}

A análise crítica se estende ao impacto dos ruídos causados pelos meios de transporte. Os trens apesar de inicialmente muito ruidosos, sempre agregaram uma carga simbólica, por representarem o ícone máximo do sucesso da indústria, como diz o autor "de todos os sons da Revolução Industrial, os dos trens parecem, ao longo do tempo, ter gerado as associações sentimentais mais atraentes." (SCHAFER, 1976, p.81) Mas não foi apenas em razão da simbologia. O trem, apesar de ser uma máquina, não possuía o som constante e desinteressante comum a estas.

Foi o automóvel, porém, e não o trem, que se tornou o meio de transporte mais popular da sociedade moderna. Como afirma o autor "o motor de combustão interna fornece agora o som fundamental da civilização contemporânea." (SCHAFER, 1976, p.82) Os ruídos do automóvel foram dominando o cenário da cidade moderna, e até hoje crescem progressivamente me 
número. Estes geram várias formas de poluição do ar, tanto sonora quanto química. Devido ao excesso de veículos, as cidades contemporâneas são caracterizadas pelo trânsito, causando um aumento brutal no tempo de deslocamento no espaço urbano. O transporte, em razão do congestionamento, se tornou o maior problema atual nas metrópoles. Sobre o estabelecimento deste estado de caos urbano, Schafer (1976, p.84) critica:

Para o homem contemporâneo urbano metade do imaginário da poesia tradicional se perdeu. A mesma coisa está acontecendo com a paisagem sonora, onde os sons da natureza estão sendo perdidos sob o bloqueio combinado de máquinas industriais e domésticas.

As fontes de ruídos excessivos que são lançados em meio urbano, e os responsáveis não são punidos de forma eficiente. As primeiras legislações sobre o ruído visavam, como coloca Schafer, sobre a década de 1970 no Canadá:

O que estamos testemunhando nas últimas campanhas de redução do ruído não é tanto uma tentativa de silenciar o mundo, mas uma tentativa de arrancar o 'Ruído Sagrado' da indústria, como um prelúdio para a descoberta de um proprietário mais confiável para quem este poder pode ser herdado. (SCHAFER, 1976, p.87)

Deve-se verificar se é possível, neste atual meio urbano tão congestionado sonoramente, que algum som se destaque em intensidade, para ser proprietário deste poder simbólico. Alguns eventos culturais, como o Carnaval e seus trios elétricos, tentam aumentar sua música a níveis de pressão que podem causar surdez. Porém, entra-se agora de uma nova fase, na qual o ambiente é tão hostil e ruidoso, que o Homem se volta para sua individualidade, na tentativa de estabelecer um universo particular melhor.

\section{REVOLUÇÃO ELÉTRICA}

Posterior a industrial, Schafer define a Revolução Elétrica como uma grande contribuinte para outra transformação na paisagem sonora, e nos modos de vida da população, devido a nova capacidade de transmissão do som, como descreve:

Os três mecanismos de som mais revolucionários da Revolução Elétrica foram o telefone, o fonógrafo e o rádio. Com o telefone e o rádio, o som não estava mais ligado ao seu ponto original no espaço; com o fonógrafo este foi libertado de seu ponto original no tempo. (SCHAFER, 1976, p.89)

O que o autor chama de fonógrafo, é de fato, o primeiro equipamento para gravação sonora. Possibilitar novas interações com o som, mudou a compressão do Homem do tempo e espaço. Neste momento, a paisagem sonora se transformou definitivamente, uma vez que agora não se tratava apenas do surgimento de novos sons de máquinas, mas sim, uma mudança radical da relação entre o Homem e os sons do ambiente, como observa Schafer (1976, p.88): 


\begin{abstract}
Os benefícios da transmissão eletroacústica e reprodução de som são muito comemorados, mas não devem obscurecer o fato de que, precisamente no momento em que Hi-fi estava sendo organizada, a paisagem sonora mundial estava entrando em uma condição Lo-fi permanente.
\end{abstract}

O Homem não precisava mais prestar atenção nos sons a sua volta, não só porque estes não são mais interessantes e variados, mas em razão de que agora pode controlá-los. Pode falar com alguém ao telefone, escutar uma informação ou uma música, quando quiser. Se achá-la agradável, pode gravá-la para escutar depois. Esta liberdade de articulação do som faz com que o Homem não dê valor ao ruído momentâneo, ou até que esteja entretido com ruídos artificiais escolhidos para seu 'mundo particular'. Como coloca o autor:

Paredes costumavam existir para isolar sons. Hoje paredes sonoras existem para isolar. Da mesma forma, a amplificação intensa da música popular não estimula a sociabilidade tanto quanto esta expressa o desejo de experimentar a individuação, a solidão, a retirada. Para o homem moderno, a barreira de som tornou-se tanto um fato quanto a parede no espaço. (SCHAFER, 1976, p.96)

Os novos sons podem atrapalhar a percepção dos naturais ou originais, e até dificultar a concentração do Homem em outras tarefas, e desta forma estão limitando a qualidade da produção cultural da sociedade contemporânea. O autor acredita que "A capacidade do telefone para interromper o pensamento é importante, pois, sem dúvida, contribuiu em boa parte para a abreviatura de prosa escrita e para o discurso entrecortado de tempos modernos." (SCHAFER, 1976, p.89) Além disso, certos sons podem ter impacto global, como observa abaixo:

Desde a invenção de equipamentos eletroacústicos para a transmissão e o armazenamento de som, qualquer som, não importa quão pequeno, pode ser aumentado e enviado para todo o mundo, ou gravado em fitas para as gerações do futuro. Nós separamos o som da fonte sonora. (SCHAFER, 1976, p.90)

Os pesquisadores da paisagem sonora estão preocupados com mudanças na percepção e no comportamento da sociedade em relação aos ruídos ambientais, porque somente com base nestas transformações do modo de compreensão que é possível avaliar a paisagem sonora contemporânea. Schafer sintetiza sobre a década de 1970 que "cria-se uma paisagem sonora sintética em que os sons naturais estão se tornando cada vez mais não naturais, enquanto os substitutos, feitos por máquinas, estão fornecendo os sinais que dirigem a vida moderna." (SCHAFER, 1976, p.91) Os sons da máquina passam a dar o ritmo da vida contemporânea. Percebe-se que é possível usar a transmissão sonora para influenciar e moldar uma cultura, e que a publicidade e o marketing têm tanto poder na Era moderna. 


\section{CONCLUSÃO SOBRE A MÚSICA DA VIDA}

Pode-se afirmar, por fim, que Schafer defende que a paisagem sonora nada mais é do que a música da vida; e critica os educadores musicais por separarem a música absoluta, relativa a outras épocas, do contexto sonoro presente:

Se há um problema de poluição sonora no mundo de hoje é, sem dúvida, em grande parte, devido ao fato de que os educadores musicais não conseguiram passar ao público a consciência total da paisagem sonora, que desde 1913, deixou de ser divisível em reinos musical e não musical. (SCHAFER, 1976, p.111)

Talvez a separação entre os reinos musical e não musical se deu devido a certa competição entre a música clássica e as novas tecnologias. Como observa o autor, apesar do poder musical inquestionável de uma orquestra, o amplificador consegue ser superior em potência:

Assim como a Revolução Elétrica estendeu o motivo de poder imperialista da Revolução Industrial, mas com maior finesse, então o amplificador substituiu a orquestra como a grande arma para dominar o espaço acústico. (SCHAFER, 1976, p.114)

Como resultado, grandes compositores passaram a escrever músicas mais leves, voltadas para a transmissão pelo radio, e para serem tocadas no ambiente exterior utilizando amplificadores. Este fato pode ser considerado uma grande perda da a música clássica, porém foi uma consequência direta da possibilidade de ampliação do espaço acústico. E este fenômeno de certa forma continua, a medida que as músicas populares são cada vez mais simples, com o intuito de atingir e sensibilizar uma maior população. Na música popular atual, além da simplicidade harmônica, os jovens estão cada vez mais interessados em sons de baixa frequência. Como coloca o autor:

Se lembrarmos os efeitos vibratórios da alta intensidade, o ruído de baixa frequência, que tem o poder de 'tocar' o ouvinte, foi experimentado primeiramente com o trovão, em seguida, na igreja, onde o som do órgão tinha feito a bancos oscilares sob os cristãos, e, finalmente, havia sido transferido para as cacofonias da fábrica do século XVIII. (SCHAFER, 1976, p.115):

O som de baixa freqüência, que é menos usual na natureza, tem o poder de sensibilizar não apenas o tímpano humano, mas todo o seu corpo com sua forma de vibração. Por essa razão, que as caixas de som 'subwoofers' estão tão difundidas em shows ao ar livre, por exemplo em trios elétricos. No entanto, "A localização da fonte sonora é mais difícil com os sons de baixa frequência, e música ressaltando esses sons é pior em qualidade e sem direção no espaço. Em vez de enfrentar a fonte sonora, o ouvinte parece imersa nesta", descreve Schafer (1976, p.116). 
Em vez de uma música direcionada e com clareza de informação, na baixa freqüência não é evidente nem a localização da fonte sonora, porque se trata de um som disperso; mas de qualquer forma, é um som mais abrangente em termos de espaço acústico, e possibilita como popularmente se diz, 'sentir a música' no corpo. Como se somente as intensidades absurdas não fossem suficientes para atrair a atenção do público atual.

Agora, o grande problema do aumento de fontes sonoras urbanas, e a grande intensidade destes novos ruídos, ficaram esquecidos pelo poder público. As cidades foram construídas de forma desordenada, sem planejamento urbano prévio, muito menos em relação a administração de seus ruídos. A poluição sonora é uma problemática que assombra até prósperas metrópoles do século XXI. Como simplifica Schafer, "a medida que a intensidade da paisagem sonora moderna ou da música moderna aumenta, a tranquilidade diminui." (SCHAFER, 1976, p.115) Perdeu-se a tranquilidade de tempos passados.

O fenômeno atualmente identificado é a total negação da paisagem sonora natural e artificial estabelecida em espaço público urbano, através do confinamento em espaços fechados e privados. O exemplo mais radical é o uso de fones de ouvido, com os quais o Homem pode caminhar pela cidade ouvindo qualquer som que desejar. Até mesmo o canto de pássaros ou o som da queda d'água de uma cachoeira. O cenário estabelecido se tornou bizarro, tamanho o distanciamento da realidade coletiva. O número de atropelamento a pedestres aumentou, entre outros fatores, porque estes não são mais capazes de ouvir buzinas de alerta. Como observa Schafer (1976, p.119):

O mais recente espaço acústico privado é produzido escutando fones de ouvido, porque mensagens recebidas nestes são sempre propriedade privada. "Head-space" é uma expressão popular usada pelos jovens, referindo-se a geografia da mente, que não pode ser alcançada por nenhum telescópio.

O individualismo aparece de forma exasperada, uma vez que o espaço coletivo é tão hostil. 0 domínio da reprodução do som conseguiu ampliar tanto o seu espaço acústico, que atingiu até mesmo o "Head-space" ou espaço da mente do Homem. Parece a liberdade de escolha de cada indivíduo, mas na verdade é uma alienação de realidade urbana:

Quando o som é conduzido diretamente através do cérebro do ouvinte que utiliza fones de ouvido, ele não está mais se importando com eventos no horizonte acústico; não está mais cercado por uma esfera de elementos móveis. Ele é a esfera. Ele é o universo. (SCHAFER, 1976, p.119)

Dado este panorama do que se transformou a paisagem sonora atual das grandes cidades, devido ao tamanho descontrole; e no grande impacto negativo que este cenário gerou aos seus habitantes; e fundamental enfrentar esta temática de forma efetiva. $O$ estudo da acústica ambiental deve se difundir para atender a escala do problema, o que evidencia a necessidades de outros trabalhos acadêmicos no mesmo tema. 


\section{REFERÊNCIAS}

HEMPTON, Gordon; GROSSMANN, John. One Square Inch of Silence: One Man's Quest to Preserve Quiet. Washington: Free Press Simon \& Schuster, 2010.

SCHAFER, R. Murray. The Soundscape. Destiny Books, Vancouver, 1993.

SCHMID, Aloísio L. A idéia de conforto - Reflexões sobre o ambiente construído. Curitiba: Pacto Ambiental, 2005.

SOUZA, Léa C. L.; ALMEIDA, Manuela G.; BRAGANÇA, Luís. Bê-a-bá da acústica arquitetônica. São Carlos: Edufscar, 2009. 